\title{
etymologia
}

\section{Ronnie Henry}

\section{Cronobacter sakazakii [kro'no-bak"tər sak'ə-zak"ee-i]]}

$\mathrm{T}$ he first documented isolation of what would become known as Cronobacter sakazakii was from a can of dried milk in 1950, although these organisms have likely existed for millions of years. In 1980, John J. Farmer III, proposed the name Enterobacter sakazakii for what had been known as "yellow-pigmented E. cloacae," in honor of Japanese bacteriologist Riichi Sakazaki. Over the next decades, E. sakazakii was implicated in scores of cases of meningitis and sepsis among infants, frequently in association with powdered infant formula. In 2007, the genus Cronobacter was created to accommodate the biogroups of E. sakazakii, with $C$. sakazakii as the type species. The genus was named for Cronos, the Titan of Greek myth, who devoured his children as they were born.

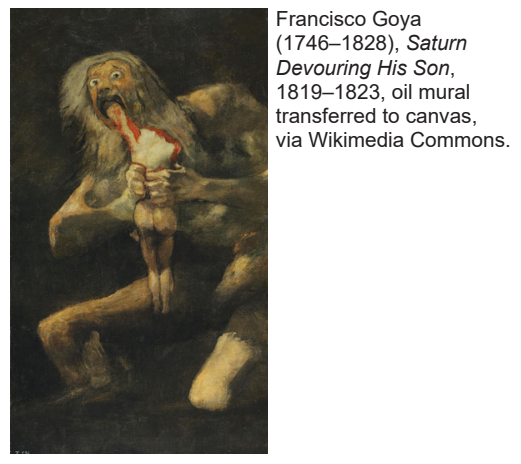

\section{Sources}

1. Farmer JJ III. My 40-year history with Cronobacter/ Enterobacter sakazakii-lessons learned, myths debunked, and recommendations. Front Pediatr. 2015;3:84. http://dx.doi.org/10.3389/fped.2015.00084

2. Farmer JJ, Asbury MA, Hickman FW, Brenner DJ. The Enterobacteriaceae Study Group. Enterobacter sakazakii: a new species of "Enterobacteriaceae" isolated from clinical specimens. Int J Syst Evol Microbiol. 1980;30:569-84.

3. Iversen C, Mullane N, McCardell B, Tall BD, Lehner A, Fanning S, et al. Cronobacter gen. nov., a new genus to accommodate the biogroups of Enterobacter sakazakii, and proposal of Cronobacter sakazakii gen. nov., comb. nov., Cronobacter malonaticus sp. nov., Cronobacter turicensis sp. nov., Cronobacter muytjensii sp. nov., Cronobacter dublinensis sp. nov., Cronobacter genomospecies 1, and of three subspecies, Cronobacter dublinensis subsp. dublinensis subsp. nov., Cronobacter dublinensis subsp. lausannensis subsp. nov. and Cronobacter dublinensis subsp. lactaridi subsp. nov. Int J Syst Evol Microbiol. 2008;58:1442-7. http://dx.doi.org/ '10.1099/ijs.0.65577-0

Address for correspondence: Ronnie Henry, Centers for Disease Control and Prevention, 1600 Clifton Rd NE, Mailstop E28, Atlanta, GA 30329-4027, USA; email: boq3@cdc.gov

\section{No Plasmodium falciparum Chloroquine Resistance Transporter and Artemisinin Resistance Mutations, Haiti}

\section{Jeanne P. Vincent, Kanako Komaki-Yasuda, Alexandre V. Existe, Jacques Boncy, Shigeyuki Kano}

Author affiliations: National Center for Global Health and Medicine, Tokyo, Japan (J.P. Vincent, K. Komaki-Yasuda,

S. Kano); University of Tsukuba, Tsukuba, Japan (J.P. Vincent,

S. Kano); Laboratoire National de Santé Publique, Port-au-Prince, Haiti (A.V. Existe, J. Boncy)

DOI: https://doi.org/10.3201/eid2411.180738
We obtained 78 human blood samples from areas in Haiti with high transmission of malaria and found no drug resistance-associated mutations in Plasmodium falciparum chloroquine resistance transporter and Kelch 13 genes. We recommend maintaining chloroquine as the first-line drug for malaria in Haiti. Artemisinin-based therapy can be used as alternative therapy.

- aiti is a unique country in the Americas because malar1 ia is caused there mainly by Plasmodium falciparum. Despite chloroquine being used for treatment of malaria since $1955, P$. falciparum is generally still susceptible to this drug (1). Thus, chloroquine, plus a single dose of the gametocytocidal drug primaquine, is still the first-line treatment for uncomplicated malaria in Haiti, as indicated by the ministry of health. This regimen began to be challenged 9 years ago after a study reported chloroquine-resistant 
haplotypes in Haiti (2). Since that time, other studies have reported no or few chloroquinine-resistance haplotypes (36 ), but an in vivo study reported a decrease in susceptibility to this drug (7) .

Artemisinin, has been used only sporadically in Haiti, but it was recently implemented by health authorities to be the second-line antimalarial drug. We evaluated 2 drug resistance markers, the $P$. falciparum chloroquine resistance transporter $(p f c r t)$ gene and the artemisinin resistance gene Kelch 13 (k13), in malaria parasites in Haiti to determine prevalences and provide information and recommendations for clinical practice to support malaria elimination efforts.

We conducted an epidemiologic survey during the summer of 2017. The study protocol was reviewed and approved by the Ethics Committee of the National Center for Global Health and Medicine (reference no. NCGMG-002260-00) in Japan and the National Bioethics Committee (reference no. 1617-48) in Haiti.

We recruited febrile patients at 3 public hospitals in 3 departments in southern Haiti. We tested these patients by using a rapid diagnostic test (SD Bioline Malaria Ag Pf/ Pan; Standard Diagnostics, Inc., Suwon, South Korea) at the point of care. These patients were a subsample of 556 patients from which we selected 144 patients with blood samples positive for $P$. falciparum DNA by the loop-mediated isothermal amplification method (Loopamp MALARIA Pan/Pf Detection Kit; Eiken Chemical Co., Tokyo, Japan). These 144 patients were potentially eligible for genotyping analysis.

We confirmed 80 positive samples from these patients by using a nested PCR specific for the 18S rRNA gene for analysis of pfcrt and $k 13$ genes. Conditions for this nested PCR were as reported (8). We performed the second PCR with only $P$. falciparum-specific primers. We amplified the $k 13$ gene by using a modified method of Ménard et al. (9) and newly designed primers specific for the $p f c r t$ gene (Table). For $p f c r t$ or $k 13$ genes, secondary PCR products were sequenced directly.

We analyzed samples from 78 patients for $k 13$ and samples from all 80 patients for $p f c r t$. The 80 patients had a mean age of 26.97 years (range 1-70 years): 13 were from
Grand'Anse Department, 24 from Nippes Department, and 43 from Sud Department. Of these samples, 71 were also positive for the Pf-specific HRP2 band of the rapid diagnostic test but only 52 for the Plasmodium-universal LDH band. Microscopy results identified only 40 of these patients as being positive for malaria.

All samples analyzed had the wild-type amino acid sequence CVMNK at positions 72-76 of pfcrt. Resistant haplotypes of $p f c r t$ were first reported in Haiti in 5 of 79 analyzed samples from Artibonite Department (2). Others studies have reported chloroquine-resistant haplotypes in 2 travelers returning from Haiti (3), 2/901 persons with possible mixed infections (chloroquine resistant and chloroquine sensitive) (4), and 1/108 cases analyzed in which microsatellite genotyping showed that the chloroquine-resistant haplotype detected was distinct from those of parasites circulating in Haiti (5). Analysis of parasite population structure in 2 of these studies $(4,5)$ could not eliminate the possibility that these cases might be exogenous infections. In addition, Elbadry et al. did not report any chloroquine-resistant haplotypes in Haiti (6).

None of the 78 samples we tested had any resistanceassociated polymorphisms in $k 13$. Five $(6.41 \%)$ samples had a synonymous mutation at nt position 1359 (bp position T1359A, codon position G453). This mutation was previously reported in only $1 / 82$ samples in a study in Haiti (10). These findings are not an indication of artemisinin resistance because artemisinin-based combination therapy is rarely used in Haiti. However, these results are useful for following the evolution of resistance to this drug in Haiti.

In this study, we analyzed patients from areas of Haiti that have high rates of malaria transmission and found no drug resistance-associated mutations for the $p f c r t$ and $k 13$ genes. Despite the limitation of a small sample size and consideration of findings of previous studies and our recent findings, we can assert that drug-resistant haplotypes are not currently circulating in Haiti.

Affordable and widely available, chloroquine is still the treatment of choice for uncomplicated Plasmodium spp. malaria in Haiti. Artemisinin-based combination therapy can be used as an alternative treatment for persons who cannot be given chloroquine. Although post-

\begin{tabular}{|c|c|c|}
\hline Target & Primer sequences, $5^{\prime} \rightarrow 3^{\prime}$ & Primer annealing positions \\
\hline pfcrt, primary PCR & $\begin{array}{c}\text { F: ATGGCTCACGTTTAGGTGGAGGT } \\
\text { R: CGGATGTTACAAAACTATAGTTACCA }\end{array}$ & $\begin{array}{c}92-114 \\
258-283\end{array}$ \\
\hline pfcrt, secondary PCR & $\begin{array}{c}\text { F: GTCTTGGTAAATGTGCTCATGTGT } \\
\text { R: CTATAGTTACCAATTTTGTTTAAAGTTCT }\end{array}$ & $\begin{array}{l}119-142 \\
241-269\end{array}$ \\
\hline$k 13$, primary $\mathrm{PCR}$ & $\begin{array}{l}\text { F: GAAGCCTTGTTGAAAGAAGCA } \\
\text { R: CCAAGCTGCCATTCATTTGT }\end{array}$ & $\begin{array}{l}1276-1296 \\
2107-2126\end{array}$ \\
\hline$k 13$, secondary PCR & $\begin{array}{l}\text { F: GCCTTGTTGAAAGAAGCAGAA } \\
\text { R: GTGGCAGCTCCAAAATTCAT }\end{array}$ & $\begin{array}{l}1279-1299 \\
2011-2030\end{array}$ \\
\hline
\end{tabular}

*Secondary PCR products were directly sequenced by using the BigDye Terminator version 3.1 Cycle Sequencing Kit and analyzed with a 3130xl Genetic Analyzer (both from Thermo Fisher Scientific Inc., Waltham, MA, USA). F, forward; k13, Kelch 13; pfcrt, P. falciparum chloroquine resistance transporter; $R$, reverse. 
treatment follow-up visits with blood testing of malaria patients can be challenging in Haiti, healthcare professionals should strive to implement these goals. Implementation would enable continuous in vivo monitoring of drug susceptibility of parasites and provide realtime data to public health authorities to formulate evidence-based policy.

\section{Acknowledgments}

We thank Masami Nakatsu and Moritoshi Iwagami for providing advice on analysis of the $k 13$ gene and the Eiken Chemical Co., Ltd. (Tokyo, Japan), for providing technical advice on loopmediated isothermal amplification.

S.K. was partly supported by the Research Program on the Challenges of Global Health Issues: US-Japan Cooperative Medical Sciences Program (grant 16jk0210006h0001).

\section{About the Author}

Dr. Vincent is a doctoral candidate in the Department of Tropical Medicine and Malaria of the Research Institute National Center for Global Health and Medicine, Tokyo, Japan. Her research interests include Plasmodium biology, malaria diagnosis, field studies for controlling malaria, and other public health issues.

\section{References}

1. von Fricken ME, Weppelmann TA, Hosford JD, Existe A, Okech BA. Malaria treatment policies and drug efficacy in Haiti from 1955-2012. J Pharm Policy Pract. 2013;6:10. http://dx.doi.org/10.1186/2052-3211-6-10

2. Londono BL, Eisele TP, Keating J, Bennett A, Chattopadhyay C, Heyliger G, et al. Chloroquine-resistant haplotype Plasmodium falciparum parasites, Haiti. Emerg Infect Dis. 2009;15:735-40. http://dx.doi.org/10.3201/eid1505.081063

3. Gharbi M, Pillai DR, Lau R, Hubert V, Khairnar K, Existe A, et al.; French National Reference Center for Imported Malaria Study. Chloroquine-resistant malaria in travelers returning from Haiti after 2010 earthquake. Emerg Infect Dis. 2012;18:1346-9. http://dx.doi.org/10.3201/eid1808.111779

4. Charles M, Das S, Daniels R, Kirkman L, Delva GG, Destine R, et al. Plasmodium falciparum K76T pfcrt gene mutations and parasite population structure, Haiti, 2006-2009. Emerg Infect Dis. 2016;22:786-93. http://dx.doi.org/10.3201/eid2205.150359

5. Morton LC, Huber C, Okoth SA, Griffing S, Lucchi N, Ljolje D, et al. Plasmodium falciparum drug-resistant haplotypes and population structure in postearthquake Haiti, 2010. Am J Trop Med Hyg. 2016;95:811-6. http://dx.doi.org/10.4269/ajtmh.16-0214

6. Elbadry MA, Existe A, Victor YS, Memnon G, Fukuda M, Dame JB, et al. Survey of Plasmodium falciparum multidrug resistance-1 and chloroquine resistance transporter alleles in Haiti. Malar J. 2013;12:426. http://dx.doi.org/10.1186/1475-2875-12-426

7. Raccurt CP, Brasseur P, Cicéron M, Parke DM, Zervos MJ, Boncy J. In vivo study of Plasmodium falciparum chloroquine susceptibility in three departments of Haiti. Malar J. 2017;16:313. http://dx.doi.org/10.1186/s12936-017-1961-2

8. Komaki-Yasuda K, Vincent JP, Nakatsu M, Kato Y, Ohmagari N, Kano S. A novel PCR-based system for the detection of four species of human malaria parasites and Plasmodium knowlesi. PLoS One. 2018;13:e0191886. http://dx.doi.org/10.1371/journal.pone.0191886
9. Ménard D, Khim N, Beghain J, Adegnika AA, Shafiul-Alam M, Amodu O, et al.; KARMA Consortium. A worldwide map of Plasmodium falciparum K13-propeller polymorphisms. N Engl J Med. 2016;374:2453-64. http://dx.doi.org/10.1056/ NEJMoa1513137

10. Carter TE, Boulter A, Existe A, Romain JR, St Victor JY, Mulligan CJ, et al. Artemisinin resistance-associated polymorphisms at the K13-propeller locus are absent in Plasmodium falciparum isolates from Haiti. Am J Trop Med Hyg. 2015;92:552-4. http://dx.doi.org/10.4269/ajtmh.14-0664

Address for correspondence: Shigeyuki Kano, Department of Tropical Medicine and Malaria, Research Institute, National Center for Global Health and Medicine, 1-21-1 Toyama, Shinjuku, Tokyo 162-8655, Japan; email: kano@ri.ncgm.go.jp

\section{Racial/Ethnic Disparities in Antimicrobial Drug Use, United States, 2014-2015}

\author{
Scott W. Olesen, Yonatan H. Grad \\ Author affiliations: Harvard T.H. Chan School of Public Health, \\ Boston, Massachusetts, USA (S.W. Olesen, Y.H. Grad); Brigham \\ and Women's Hospital, Boston (Y.H. Grad)
}

DOI: https://doi.org/10.3201/eid2411.180762

Using a US nationwide survey, we measured disparities in antimicrobial drug acquisition by race/ethnicity for 20142015. White persons reported twice as many antimicrobial drug prescription fills per capita as persons of other race/ ethnicities. Characterizing antimicrobial drug use by demographic might improve antimicrobial drug stewardship and help address antimicrobial drug resistance.

A ntimicrobial drug use varies by sex, age, and geography (1), and antimicrobial drug prescribing practice for specific medical conditions and age cohorts varies by patients' race/ethnicity (2-4). Many studies on the role of patient race/ethnicity in antimicrobial drug prescribing practice focus on acute respiratory illnesses because antimicrobial drugs are often inappropriately prescribed for these conditions. The subjective diagnostic criteria for respiratory illnesses might result in race/ethnicity influencing prescribing practice more for these illnesses than for other illnesses (4). Despite our increasing knowledge of the role of patient race/ethnicity in drug prescribing practice for specific 